\title{
A INSTALAÇÃO ETNOGRÁFICA AS MULHERES E A FIBRA: UM DIÁLOGO ENTRE ANTROPOLOGIA E ARTE
}

\author{
Diogo Dubiela ${ }^{1}$
}

\section{Introdução}

É cada vez maior no mundo contemporâneo a adesão de formas sensíveis ao círculo antropológico. Desde Malinowski através da imagem o campo antropológico vem a ser atravessado pela presença destas formas e cada vez mais o resultado etnográfico é dado nos termos de uma "estética do imaginário", algo além da palavra escrita, "num modo de dizer através das imagens aquilo que não pode ser aprendido de outra forma" (Rocha e Eckert, 2015: 84).

No âmbito de um processo de descolonização, a crise da representação na segunda metade do século XX, na Antropologia trazida à tona de maneira muito forte pelo projeto Writing Culture não se limitou ao âmbito da escrita. A própria crise em si impele à abertura a novas possibilidades de representação e interpretação, e por isso repercutiu também no plano da produção visual e sensorial. É neste contexto que se busca refletir em maior profundidade acerca dos modos de exibição da produção etnográfica e, por sua vez, as próprias bases constitutivas desta produção, no sentido de uma presença maior da interlocução na cena antropológica.

Novas formas de produzir conhecimento antropológico, novas maneiras de documentar e expressar a relação com o outro se revelam necessárias. Neste sentido, busco refletir sobre a noção de instalação etnográfica como uma nova possibilidade de representação e interpretação visual. Na busca por uma relação dialógica e simétrica na prática etnográfica, a instalação etnográfica coloca-se como inovação, advém de um espaço epistêmico intersticial e, desta forma, constitui-se quase como uma provocação à forma de materialização canônica do conhecimento antropológico.

Como condição básica, a instalação etnográfica brota da experiência etnográfica, e vice-versa. Pode ser o resultado ou início de um trabalho de campo, esse movimento paradoxal de envolvimento e distanciamento, mais ou menos objetividade, nunca neutralidade, sempre negociação. Desde (Clifford, 1998) entende-se o curso geral da pesquisa etnográfica como uma grande negociação. A etnografia passa cada vez mais

\footnotetext{
${ }^{1}$ Universidade Federal do Rio Grande do Sul, Brasil.
} 
a ser engendrada por uma dinâmica de (re)negociação continuada de sentido da sua produção, dado o contexto de descolonização em que se tornam visíveis as mudanças sociais e, em conformidade com elas, as mudanças nas estruturas narrativas (Brunner, 1986) em Antropologia. Assim, temos a instalação etnográfica como uma nova possibilidade nas formas de narrar a experiência etnográfica.

A relação dialógica entre Antropologia e Arte constitui o background da forma em questão. A instalação etnográfica é aqui concebida como uma composição diacrítico-estética, a Antropologia como meio para sensibilizar e a arte como meio de documentar o mundo, e vice-versa. Uma congruência marcante entre o ato de fazer arte e o papel da criatividade no processo etnográfico. Com o passar do tempo um jogo de apropriação metodológica intercampos se dá a ver aos nossos olhos. São muitas as similitudes, assim como as diferenças.

\section{A instalação etnográfica As Mulheres e a fibra}

A instalação etnográfica As mulheres e a fibra integra um processo etnográfico urbano e visual iniciado em 2013 com as mulheres do grupo Art\&Mãe no bairro Bom Jesus, cidade de Porto Alegre - Brasil. O Art\&Mãe é um grupo de mulheres que desenvolve trabalhos artesanais com fibra de garrafa PET. São almofadas, travesseiros, mantas, cachicóis, tapetes, bonecas de bano, e o edredom de fibra de garrafa PET, que é o produto mais tradicional do grupo. A produção é autônoma e sua circulação opera uma economia solidária no bairro e entorno, além de participações do grupo em feiras e eventos.

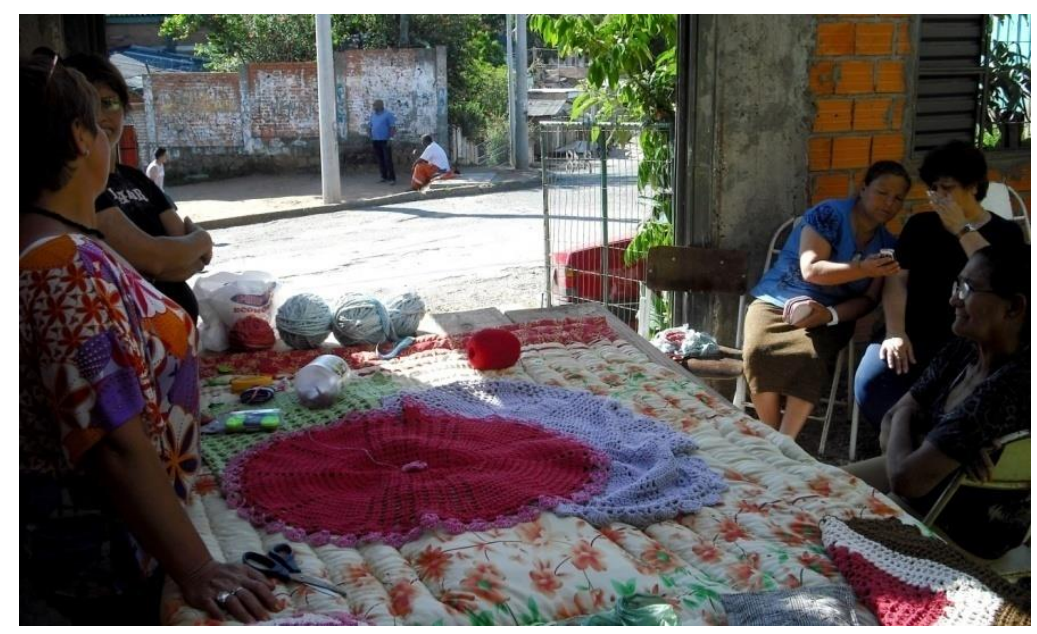

As mulheres do grupo Art\&Mãe em trabalhos com a fibra, croché e edredom. Foto: Diogo Dubiela. 
A experiência é preponderante para a percepção, diferentes experiências levam a diferentes percepções. Em uma visão fenomenológica da percepção considera-se que o sentido não se encontra em nenhum dos pólos considerados isoladamente, mas surge da relação que se estabelece entre eles (Merleau-Ponty, 1999). Desta forma, o sentido não está nas mulheres (sujeito) nem na fibra (objeto), fenomenologicamente ele está na relação entre as mulheres e a fibra.

A relação entre trabalhos e sentidos das mulheres interlocutoras com a fibra construiu-se como objeto da pesquisa. Procurei entender como o grupo se organiza, o que regula a sua produção e circulação, enfim, o que faz as mulheres sentirem-se pertencentes ao grupo Art\&Mãe. Como estratégia dei atenção à reconstituição da história do grupo, através de entrevista e captura de depoimentos das interlocutoras durante a interação com elas no trabalho de campo. Uma interação mediada pela câmera, pois o tempo todo interagi com as interlocutoras com a câmera na mão.

Todo trabalho de campo foi orientado para a construção de uma narrativa etnográfica visual, que, em sua totalidade, constitui-se em um conjunto composto pelo filme etnográfico, o ensaio fotoetnográfico e a instalação etnográfica. Como condição para a construção de uma estética ética do processo intersubjetivo em questão, trago a perspectiva de um trabalho que seja engendrado por uma dinâmica de (re)negociação continuada de sentido de sua produção. Para tal, como parte desta dinâmioca, estabeleci com as interlocutoras na pesquisa um jogo de feedbacks. O feedback consiste na exibição das imagens fotográficas impressas e das imagens em movimento já enquanto uma composição após certo trabalho de montagem, mesmo que tais imagens já tivessem sido mostradas às interlocutoras no display da câmera, logo após terem sido feitas. 


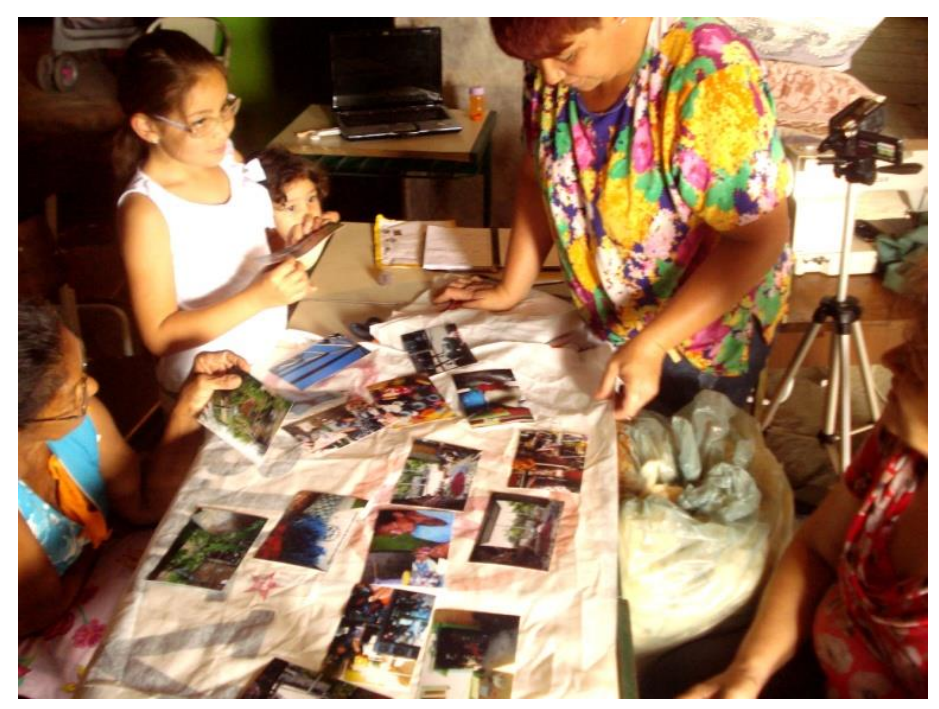

Um dos feedbacks realizados com o grupo durante o trabalho de campo. Foto: Diogo Dubiela.

A fibra adquire várias formas. Ora aparenta-se com uma estopa, ora com novelos de lã, ora ainda com a própria forma do algodão. Mas não é estopa nem lã nem algodão. É algo que parece mas não é. Engana. Por fim, surpreende. É o que ninguém imagina. É a garrafa PET que passa pelas mãos de muitos de nós no cotidiano na cidade, garrafa de água, refrigerante e/ou suco. Plástico que permeia a vida contemporânea na cidade em diferentes formas e contextos. Plástico que é o resíduo do resíduo e que estas mulheres reinserem na circulação de uma forma criativa, autônoma e solidária.

$\mathrm{Na}$ indústria as garrafas de PET coletadas são lavadas e trituradas, para em seguida o plástico ser derretido em um procedimento que dá a forma do fio. Um tipo de fio para a linha industrial de ecotêxteis. No entanto, deste processo resulta um novo resíduo, que é doado diretamente da indústria para o grupo. As mulheres do grupo Art\&Mãe através de seus trabalhos com a fibra reinserem na circulação o resíduo do resíduo. A garrafa PET inicialmente jogada no lixo, volta a estar disponível para o consumo, porém sob outro aspecto e com outras funções, em virtude do trabalho criativo, autônomo e solidário do Art\&Mãe.

Para compreender a organização do grupo utilizo o conceito de sociabilidade, criado no campo da Sociologia por Georg Simmel (Frúgoli Jr., 2007). Ao expor sobre as formas de sociabilidade em Simmel, Frúgoli lembra que para o autor alemão a sociedade seria a modalidade de interação entre os indivíduos, de modo que o status nascendi da sociedade residiria nos processos de interação microssociológicos através dos quais se constituem associações. O conceito de sociabilidade constitui-se como "um 
tipo ideal entendido como o 'social puro', forma lúdica arquetípica de toda socialização humana, sem quaisquer propósitos, interesses ou objetivos que a interação em si mesma" (Frúgoli Jr., 2007: 9).

Deste modo, compreendo o grupo de mulheres Art\&Mãe como uma forma de sociabilidade feminina. O que engendra o pertencimento ao grupo é o fato de ser mulher e participar de uma forma de sociabilidade feminina em um espaço de liberdade de gênero, apoio mútuo e autonomia através de trabalhos com a fibra.

E a fibra sobre a tela espera

$\mathrm{O}$ gesto e as cores

Espera a imaginação,

Pois conceituação se há.

Uma casa, uma flor, árvore a frutificar.

Esta forma ainda estranha,

Orgânica e sensível.

Presente do acaso.

[Pois]

O sensível e o inteligível,

Hão de dialogar. 


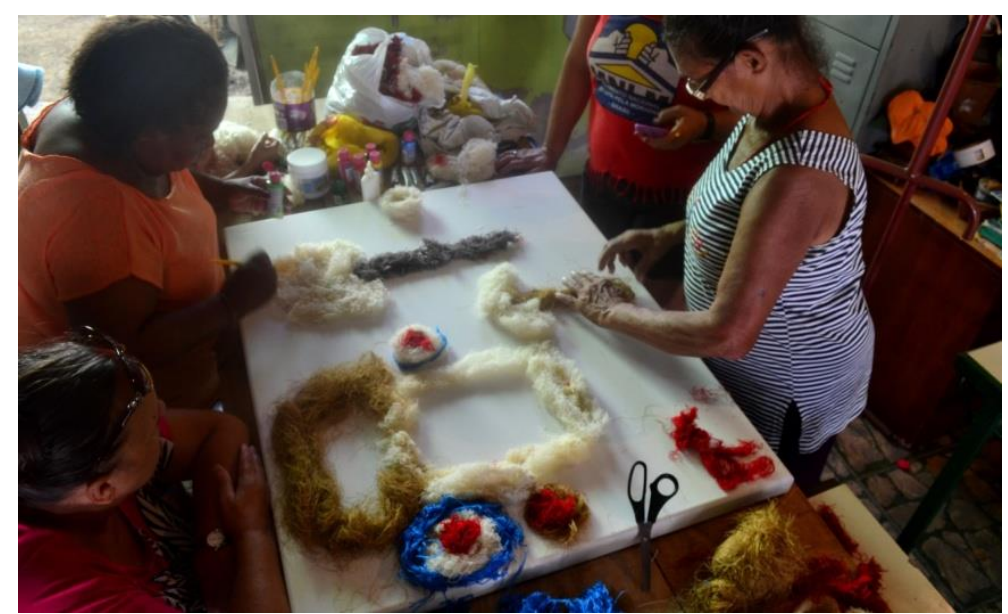

As mulheres do grupo Art\&Mãe durante a oficina de criação da tela coletiva. Foto: Diogo Dubiela.

Como parte do trabalho de campo, propus a realização de uma oficina com as mulheres, com o objetivo de criarmos uma tela coletiva, utilizando tintas e fibra de garrafa PET. A oficina se insere nesse contexto como recurso metodológico para acessar a percepção sensível das mulheres em relação à fibra, ao proporcionar outra sensibilização delas com aquele material em uma experimentação plástica. Uma experienciação sensível coletiva com a fibra. Na perspectiva de não "prescindir do estudo das formas sensíveis através das quais o pensamento humano opera sentido para o mundo" (Rocha e Eckert, 2015: 24).

Foram dois dias de trabalho de campo para a criação da tela coletiva, denominada pelas mulheres de Art\&Mãe. Algumas se envolveram mais rápido que outras, a interlocutora principal Cenira invoca a filosofia do "cada um faz uma coisa", a representação da casa e árvore dão um tom lúdico à atividade. Ludicidade diacrítica se relacionarmos com a filiação do grupo com o movimento pelo direito a moradia, com o fato do espaço de produção do grupo ser parte de uma casa. A proposta delas foi de representação sua a produzir com a fibra dentro da casa. Indícios da tela como uma paisagem. Uma paisagem imaginada com tintas e fibras.

Portanto, a oficina foi um momento do processo etnográfico que consagra a imaginação criadora com o brotamento da forma sensível como parte integrante da formulação do conhecimento antropológico. Pois, segundo (Rocha e Eckert, 2015), 
a imaginação não se opõe ao real, uma vez que a função fantástica que ela realiza acompanha o engajamento mais concreto das ações do homem no mundo, sendo centro de dispositivos de saber, da estética ao conhecimento e dos seus dispositivos éticos à política (Rocha e Eckert, 2015: 29).

Segundo a interlocutora principal Cenira, "é o imaginário de cada pessoa que fez o quadro né, que fez a tela, cada um imaginou e fez, você pode imaginar qualquer outra coisa, cada um imagina o que olha ali né”.

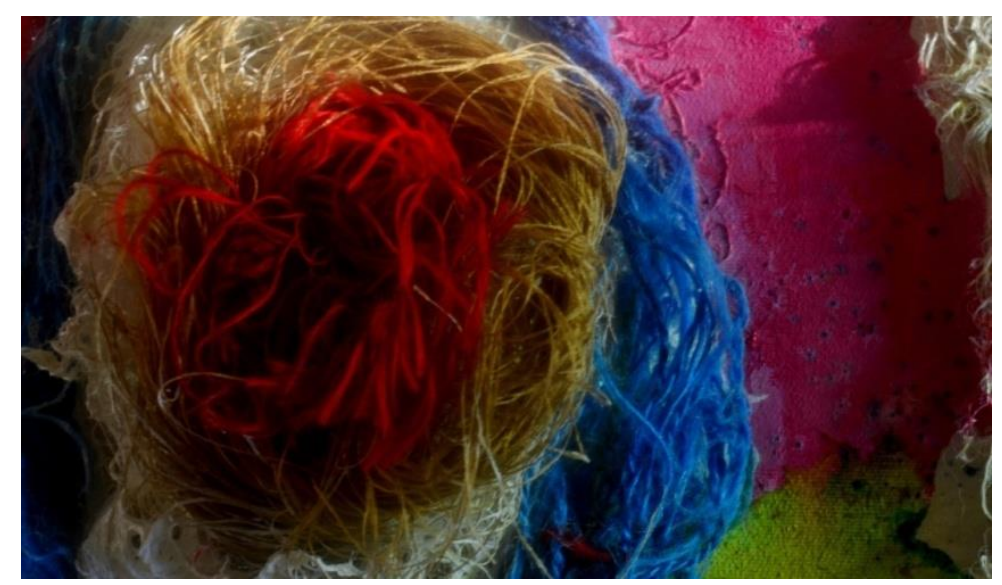

Detalhe da tela coletiva intitulada Arte\&Mãe.

Com o brotamento das telas todo processo passa a corroborar para a concepção da instalação etnográfica. Negociei com as mulheres a ideia de uma instalação com a fibra esticada no espaço, as telas, fotos e artigos confeccionados por elas com a fibra de garrafa PET.

A partir de uma parceria com o Núcleo de Antropologia Visual (NAVISUAL/UFRGS), foi viabilizada a montagem da instalação etnográfica As mulheres e a fibra na Galeria Olho Nu - IFCH/UFRGS. 


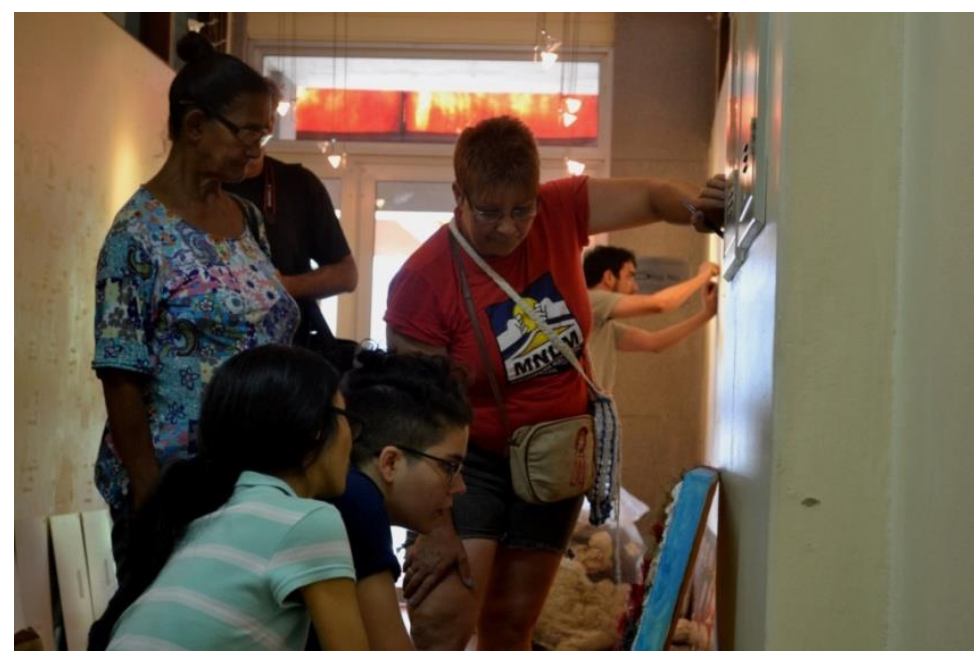

As interlocutoras Eloina e Cenira a participar da montagem da instalação etnográfica na Galeria Olho $\mathrm{Nu} / \mathrm{NAVISUAL/IFCH/UFRGS.}$

De modo a cumprir com uma dinâmica de (re)negociação continuada de sentido da produção etnográfica e o caráter colaborativo do processo com as mulheres do grupo Art\&Mãe, negociei com elas o projeto expográfico da instalação, o qual foi entregue à coordenação da galeria como condição do edital para ocupação daquele espaço expositivo. Foi viabilizado também um carro da universidade para transportar as interlocutoras até a galeria, para que estivessem presentes nos dias da montagem e de abertura da instalação etnográfica.

A presença das mulheres no momento da montagem ${ }^{2}$ foi de suma importância, na ocasião elas puderam negociar ativamente a montagem da instalação comigo e com a equipe NAVISUAL/UFRGS. Juntos compusemos quadros com as fotografias, decidimos onde fixar cada tela acrílica, cada quadro de fotografias e as fibras no espaço.

2 O teaser da montagem da instalação etnográfica As mulheres e a fibra está disponível em https://www.youtube.com/watch?v=WKn2BahnMd8 


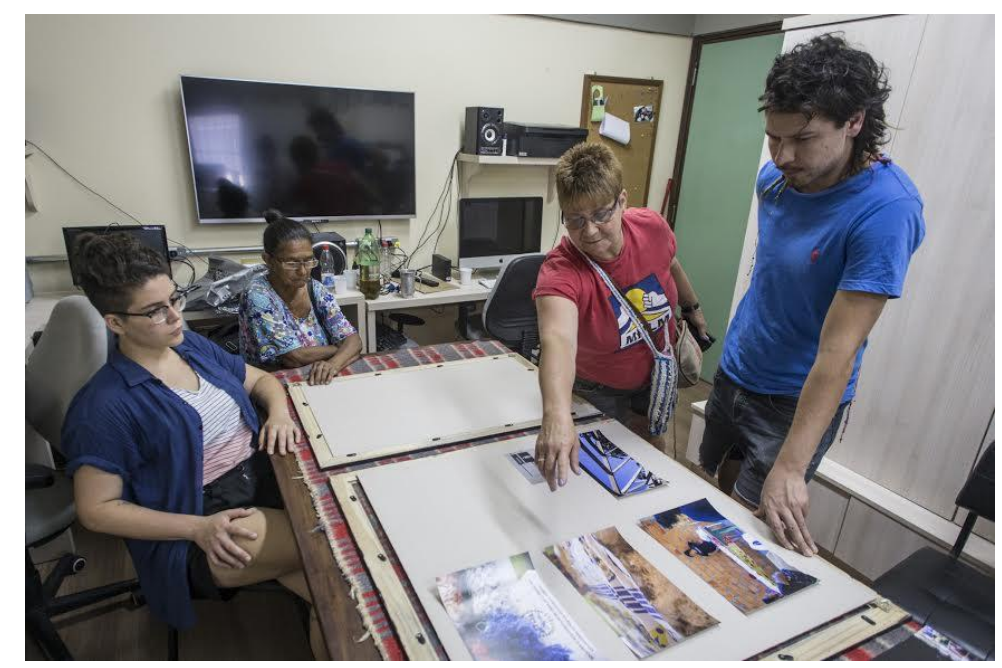

Montagem da instalação. Da esquerda para a direita: Camila Braz (NAVISUAL/UFRGS), as interlocutoras Eloina e Cenira (Art\&Mãe), e Diogo Dubiela no momento de compor os painéis com as fotografias da instalação. Foto: Fabrício Barreto.

Para o lançamento da instalação etnográfica As mulheres e a fibra, foi organizado um evento, o qual iniciou com a exibição do documentário etnográfico ${ }^{3} A s$ mulheres e a fibra. Após a exibição do documentário, ocorreu o seminário de apresentação do trabalho de pesquisa.

O videodocumentário etnográfico As mulheres $e$ a fibra está disponível em http://www.lume.ufrgs.br/handle/10183/134049. 


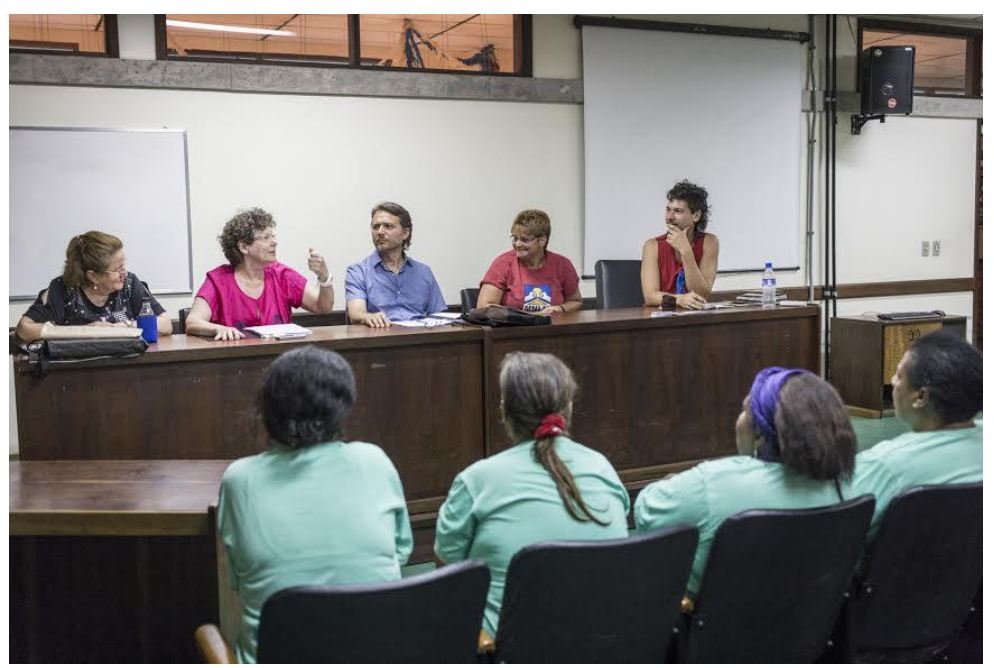

Apresentação do trabalho de pesquisa etnográfica. Em primeiro plano, mulheres do grupo Art\&Mãe assistem na primeira fila a apresentação do trabalho de pesquisa no qual são interlocutoras. Em segundo plano, compõem a mesa da esquerda para a direita: Maria Eunice Maciel (Departamento de

Antropologia/UFRGS), Cornelia Eckert (Departamento de Antropologia/UFRGS), Caleb Faria Alves (Departamento de Antropologia/UFRGS), a interlocutora principal Cenira Vargas da Silva (Art\&Mãe) e Diogo Dubiela. Foto: Fabrício Barreto.

Por fim, após o seminário, ocorreu o vernissage de lançamento da instalação etnográfica ${ }^{4}$.

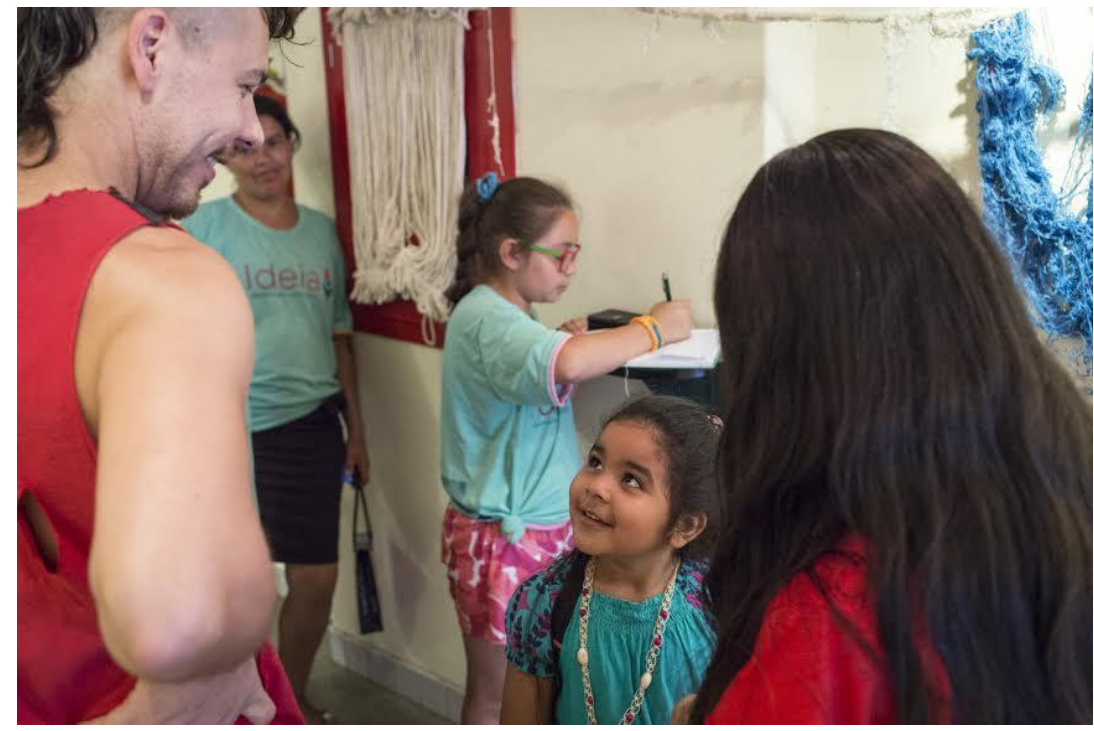

Interação durante o vernissage de lançamento da instalação etnográfica As mulheres e a fibra. Foto: Fabrício Barreto.

\footnotetext{
${ }^{4} \mathrm{O}$ registro em vídeo do evento de lançamento da instalação etnográfica As mulheres e a fibra está disponível em https://www.youtube.com/watch?v=TAED2Tx1oTs
} 
Indícios visuais de vida vivida. O processo etnográfico em questão caracteriza-se como um movimento de sensibilização do etnógrafo, da interlocução na pesquisa e de quem vê o resultado da etnografia visual. Uma forma sensível e dialógica entre o estético e o diacrítico, envolvimento e ética, Antropologia e Arte.

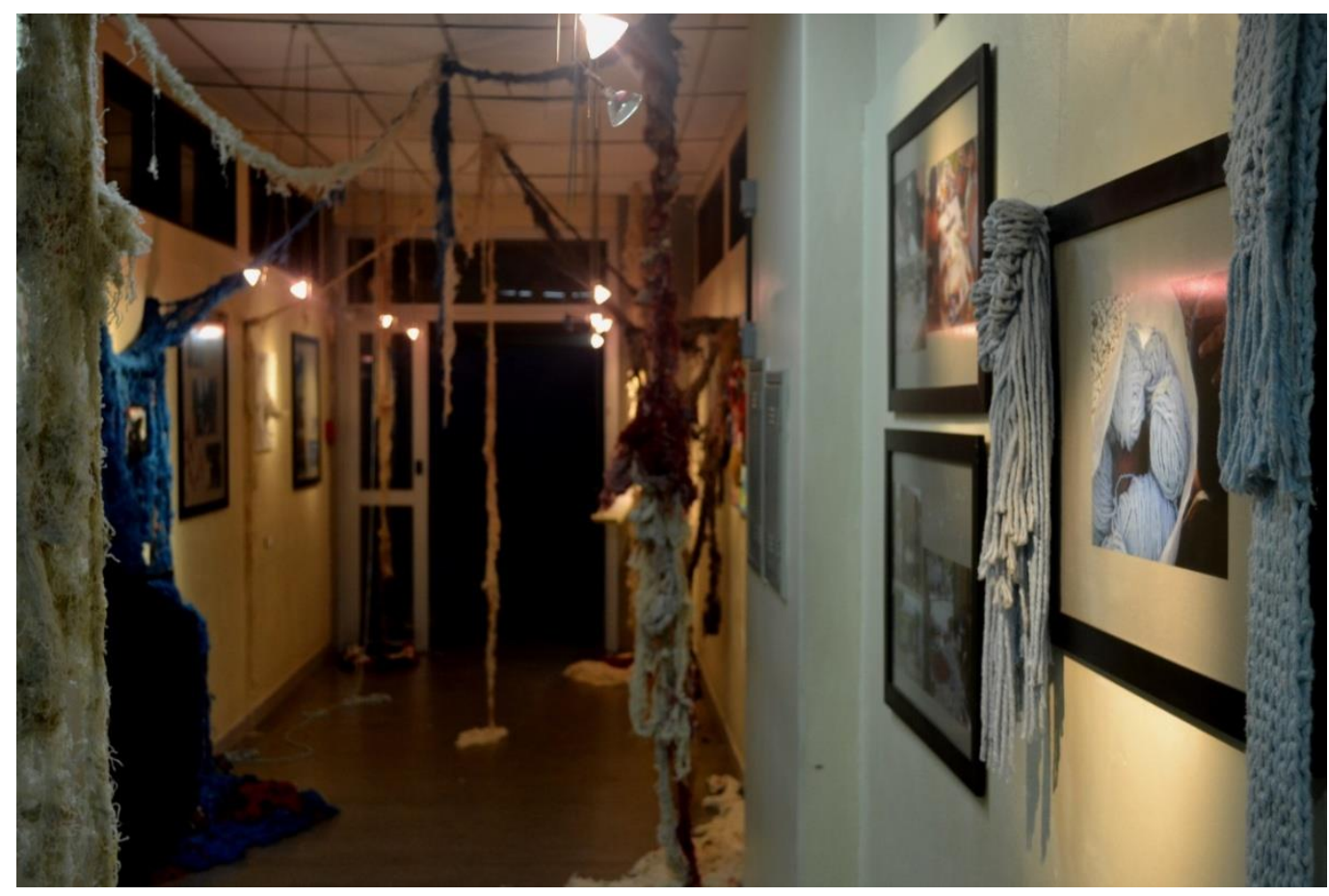

A instalação etnográfica As mulheres e a fibra exposta na Galeria Olho Nu/NAVISUAL/IFCH/UFRGS. Porto Alegre, 15 de dezembro de 2015- Brasil.

\section{Um diálogo entre Antropologia e Arte}

Após o lançamento da instalação etnográfica As mulheres e a fibra, debrucei-me mais detidamente sobre esta noção que venho a utilizar. Em busca de um contexto sobre esta noção, deparei-me com outras experiências e discursos sobre instalação etnográfica mundo afora.

Quetzil Castañeda assume o diálogo com a arte conceitual desde o campo da arqueologia. O autor Busca em seu texto colocar a instalação etnográfica como uma ferramenta metodológica útil à prática arqueológica. Para tal parte do caso da instalação etnográfica Chilam Balam, a qual se trata de uma instalação construída em 2009 com materiais arquivísticos pertencentes à história da pesquisa arqueológica patrocinada pela Carnegie Institution de Washington entre 1923 e 1941. Em um espírito de 
descolonização, estes materiais foram apresentados à comunidade maia de Chichén Itzá, em Yucatán-México, como uma forma de facilitar a reapropriação comunitária de uma história compartilhada com a arqueologia. Neste sentido, o autor discute "research in which the ethnographic installation was used as a methodological strategy to investigate the construction of a "past" community relationship with archeology" (Castañeda, 2009: 263).

Em 2011 o antropólogo e artista Lorenzo Bordonaro lança em Lisboa-Portugal a instalação etnográfica Gueto Six, resultante de sua experiência etnográfica no Bairro 6 de Maio, um bairro autoconstruído e à época em fase de demolição. O antropólogoartista utilizou materiais que sobraram da demolição das casas do bairro para construir a instalação, que após exposta no Museu da Cidade de Lisboa foi transferida para o bairro que lhe deu origem, ali permaneceu e foi destruída junto com o resto do bairro. Segundo o autor, "a ideia que esteve na origem de Ghetto Six foi a de propor intervenções que juntem arte e pesquisa, explorando, por um lado, as sobreposições entre arte contemporânea e etnografia" (Bordonaro, 2013: 26). Em 2015 Bordonaro lança no Brasil a instalação Nova Liberdade III, em Aracaju/Sergipe. Esta uma instalação construída com elementos de uma ocupação habitacional chamada Nova Liberdade III localizada na periferia de Aracaju, onde desenvolveu uma experiência etnográfica com sua turma de alunos no PPGAS/UFS.

Nuno Porto, a partir de sua experiência pessoal de participar na criação de quatro exposições no Museu de Antropologia da Universidade de Coimbra (MAUC), em Portugal, entre 1999 e 2005, ao trazer a noção de instalação etnográfica, procura distingui-la da mera exposição de objetos. Neste sentido, "installing, rather than exhibiting, has been refined as a specific knowledge-practice at the MAUC. It conceptualizes itself in opposition, for instance, to what supermarkets do, which is to put objects on display" (Porto, 2007: 193).

Em 2016, a discussão sobre instalação etnográfica como metodologia na Antropologia ganha corpo também com a realização do evento acadêmico Innovations in Ethnographic Methodology, realizado pelo Center for Ethnographic Research na Universidade da Califórnia, Berkeley. O evento com foco na etnografia como método reuniu estudiosos dos EUA e Reino Unido para mostrar as possibilidades do método etnográfico e como ele pode ser usado em conjunto com outros métodos de pesquisa. Neste evento a antropóloga e artista Cassandra Hartblay apresentou o trabalho denominado "This is not Thick Description: Conceptual Art Installation as 
Ethnographic Process", no qual argumenta sobre a sua experiência com a instalação etnográfica Do you like this installation?, que esteve exposta ao público no evento.

A experiência com a instalação etnográfica As mulheres e a fibra e demais casos mundo afora possibilita uma reflexão sobre a relação entre Antropologia e Arte. A forma como se configuram tais experiências impele a uma visão dialógica dessa relação. Por muito tempo Antropologia e Arte foram vistos como separadas, próximas nos momentos de classificação e separadas nas suas formas de representação/interpretação. Uma divisão que vem sendo questionada tanto por artistas quanto por antropólogos (as) que enxergam como potente a combinação de forças entre Antropologia e Arte.

O trânsito entre a cena artística e a antropológica pode ser visto como parte de um processo de descolonização de campos disciplinares. Na esteira de (Macdonald, 2007), tomo a chamada "crise da representação" como ponto de aproximação entre os campos disciplinares. Segundo os autores, um período que pode ser considerado como "a second age of experimentalism, associated with that post-Enlightenment "crisis of representation"' in which notions of "objectivity," 'certainty,' and "Truth,'” as well as earlier claims of transparency, have themselves come to be questioned" (Macdonald, 2007: 6). Assim, o experimentalismo volta à cena a partir do contato entre antropólogos (as) e artistas na construção de instalações etnográficas.

George Marcus, por sua vez, busca mostrar como a pesquisa de campo em artes cênicas pode informar a reinvenção da pesquisa de campo em Antropologia. A partir do exemplo do cenógrafo venezuelano Fernando Calzadilla e sua experiência de trabalho de campo como condição para a elaboração da cenografia de A casa de Bernarda Alba, de García Lorca. O cenógrafo conta que passou três meses convivendo em comunidades do interior, "seu relato do período que passou nessas cidades assemelha-se em muito com a experiência inicial de pesquisa de campo na mise-en-scène malinowskiana" (Marcus, 2004: 153).

Um reflexo da forma como o que era uma peculiaridade metodológica da Antropologia tornou-se moda no mundo das artes e humanidades. A pesquisa de campo deixou de ser uma característica do trabalho antropológico e passou a ser utilizada, reformulada, conforme cada caso, por outras áreas da produção de conhecimento. 
$\mathrm{Na}$ Antropologia, as críticas de Writing Culture dirigiram-se menos à pesquisa de campo que à escrita etnográfica. Segundo o autor,

a reflexividade crítica foi o meio de tornar visível e, deste modo, apontar para além dos tropos da escrita etnográfica, mas ao invés de romper com a mise-en-scène da pesquisa de campo, como o cronotopo a partir do qual toda esta escrita é imaginada, ela terminou por reforça-la e foi por ela ludibriada (Marcus, 2004: 136).

Para tanto, Marcus (2004) propõe substituir as noções de "distanciamento e de limitação espacial da mise-en-scène malinowskiana pela cumplicidade entre observador e observado" (Marcus, 2004: 133). Segundo Gilberto Velho, este movimento necessário de

relativizar as noções de distância e objetividade, se de um lado nos torna mais modestos quanto à construção do nosso conhecimento em geral, por outro lado permite-nos observar o familiar e estudá-lo sem paranoias sobre a impossibilidade de resultados imparciais, neutros (Velho, 1978: 5).

As apropriações artísticas do método etnográfico, sobretudo a partir de meados dos anos 1990, indica um caminho para se pensar a reinvenção da cena tradicional da pesquisa de campo em Antropologia. No campo das Artes Visuais, cabe destacar a instalação Poética dos Trançados de Ana Norogrando (2007). A artista desenvolveu um projeto que contemplou visitas às terras indígenas kaigang no Estado do Rio Grande do Sul/Brasil e, a seu pedido, em cada comunidade os indígenas confeccionaram suas peneiras, em tamanhos variados e diferenciados do tamanho original, com as quais a artista compôs a instalação, que hoje está sob guarda do Laboratório de Interculturalidade e Diversidade (LAID/UFPR), sob coordenação de Ana Elisa de Castro Freitas. Em 2008 a artista plástica e antropóloga Lídia Degarrod lançou a instalação multimídia Geography of the Imagination, no La Peña Cultural Center em California/EUA. A instalação combina arte visual e antropologia para retratar as imagens internas de migração de um grupo de imigrantes chilenos, a maioria refugiados políticos.

Neste contexto, a questão da apropriação pode constituir o motor epistemológico do diálogo entre Antropologia e Arte. São muitos os pontos de contato objetivo entre um campo e outro, como o caderno de campo na Antropologia e o caderno de anotações e esboços na Arte, ou a prática de residência artística com a prática de trabalho de campo antropológico, assim como a participação de ambas no esquema de releituras, 
citações e referências. Há um compartilhamento da mesma dimensão prática das atividades e, "com base nesse diálogo prático, as diferenças entre Arte e Antropologia deixam de ser barreira para contribuir diretamente ao desenvolvimento e afinamento das metodologias de pesquisa nos dois campos" (Malysse, 2005: 741).

No rastro de (Schneider, 2010), podemos pensar em uma convergência intensa entre o ato de fazer arte e o papel da criatividade no trabalho de campo, de modo que este pode ser incorporado no processo de produção artística, assim como esta tornada uma técnica de trabalho de campo. Documentação e sensibilização podem ser objetivos compartilhados entre os dois campos, por obras que reivindicam no campo da Arte seu status de crítica e mediação social e no campo da Antropologia por obras que transbordem as funções representacionais e documentais tradicionais.

A invés do distanciamento

O envolvimento

Não só a razão, mas

Também a sensação.

O coração a bater

\section{Pelo encontro que pulsa.}

A etnografia enquanto

Indício de vida

Brotamento

Transbordamento dos sentidos

(re)criação de si

Com o outro 


\section{Considerações finais}

Dentro de um movimento com o espírito de descolonização, que visa uma presença maior da interlocução no processo etnográfico dado a ver, As mulheres e a fibra se insere como produção intersticial, como experiência experimental na prática antropológica e artística contemporânea. Impele à discussão sobre uma forma prática e conceitual denominada instalação etnográfica, de modo que se estabelece o diálogo entre Antropologia e Arte como seu background.

Sendo assim, a instalação etnográfica é uma composição diacrítico-estética no espaço, como prática antropológica contemporânea. É elaborada a partir de uma relação dialógica entre Antropologia e Arte, resulta da busca por uma apresentação sensível, que inscreva o espaço de intersubjetividade construído pela pesquisadora ou pesquisador e sua interlocução. Através da articulação de diferentes movimentos de abstração em distintas formas de linguagem, a saber, fotografia, vídeo, telas, desenhos e elementos alçados ao status de diacrítico-estéticos durante o processo etnográfico. A instalação etnográfica inscreve universos e relações, é feita de presenças e ausências, carrega sentidos ditos e não ditos, trata-se de uma poética visual do indício de vida, uma criação antropológica, uma inquietação, um querer.

\section{Referências}

BORDONARO, L. Ghetto Six. Uma intervenção artística "ethnography-based". In Cadernos de Arte e Antropologia, n. 1/2013, 25-30.

BRUNER, E. Ethnography as narrative. In TURNER, V._ BRUNER, E. The Anthropology of Experience. Urbana e Chicago University of Illinois Press, 1986.p. 139-155.

CASTANEDDA, Q. The 'past' as transcultural space: using ethnographic installation in the study of Archaeology. In Public Archaeology: archaeological ethnographies, vol. 8 n. 2-3, 2009, 262-282.

CLIFFORD, J. A experiência etnográfica: antropologia e literatura no século XX. Rio de Janeiro: Ed. Da UFRJ, 1998.

FRUGOLI JR. H. Sociabilidade urbana. Rio de Janeiro: Zahar, 2007.

MACDONALD, S; BASU, P. Introduction: experiments in exhibition, ethnography, art and science. In MACDONALD, S; BASU, P. Exhibition experiments. Maldem, MA: Blackwell Publishing. 2007, 1-24.

MALYSSE, S. Entre arte e antropologia: diálogos e apropriações. In Revista de Antropologia, São Paulo, v. 48, n. 2, p. 739-747, dez 2005.

MARCUS, G. E. O intercâmbio entre arte e antropologia: como a pesquisa de campo em artes cênicas pode informar a reinvenção da pesquisa de campo em antropologia. In Revista de Antropologia, v. 47, n. 1, p. 133-158, jan. 2004.

MERLEAU-PONTY, M. Fenomenologia da percepção. São Paulo: Martins Fontes, 1999. 
PORTO, N. From exhibiting to installing ethnography experiments at the Museum of Anthropology of the University of Coimbra, Portugal, 1999-2005. In MACDONALD, S; BASU, P. Exhibition experiments. Maldem, MA: Blackwell Publishing. 2007, 175-196.

ROCHA, A. L. C.; ECKERT, C. A preeminência da imagem e do imaginário nos jogos da memória coletiva em coleções etnográficas. Brasília: ABA, 2015.

SCHNEIDER, A.; WRIGHT, C. Between Art and Anthropology: Contemporary Ethnographic Practice. London, Bloomsbury Publishing. 2010.

VELHO, G. Observando o familiar. In: NUNES, Edson de Oliveira (org). A aventura sociológica. Rio de Janeiro: Zahar Editores, 1978.

Recebido em: 30/01/2017. Aprovado em: 13/04/2017. 